\title{
Dynamic Changes Analysis and Hotspots Detection of Land Use in the Central Core Functional Area of Jing-Jin-Ji from 2000 to 2015 Based on Remote Sensing Data
}

\author{
Yafei Li, ${ }^{1}$ Gaohuan Liu, ${ }^{2}$ and Chong Huang ${ }^{2}$ \\ ${ }^{1}$ Civil Aviation University of China, Tianjin 300300, China \\ ${ }^{2}$ Institute of Geographic Sciences and Natural Resources Research, CAS, Beijing 100101, China \\ Correspondence should be addressed to Yafei Li; commissioner@126.com
}

Received 4 January 2017; Revised 11 March 2017; Accepted 2 April 2017; Published 3 May 2017

Academic Editor: Hasi Bagan

Copyright (C) 2017 Yafei Li et al. This is an open access article distributed under the Creative Commons Attribution License, which permits unrestricted use, distribution, and reproduction in any medium, provided the original work is properly cited.

\begin{abstract}
The article uses GIS spatial analysis and grid technologies to study the dynamic changes, hotspot regions, and driving forces in land use of the central core functional area of Jing-Jin-Ji. The research results are as follows: from 2000 to 2015, the main types of land use in the central core functional area of Jing-Jin-Ji are cultivated land, woodland, and built-up land. In the period of 2005-2010, the transfer between built-up land and cultivated land was frequent. The dynamic degree of single land use in unused land was highest. It also finds out that the dynamic degree of the integrated land use from 2005 to 2010 was higher. The center of gravity transfer of the dynamic degree of integrated land use was concentrated in research area. As for the hotspots, their number and scope are increasing, and the positions located in the edge of original main urban area and developed transportation network. The main characteristics of land use dynamic change in the study area are the rapid decrease of cultivated land area and rapid growth of built-up land. The spatial agglomeration of economic factors caused by human activities has an important influence on the spatial and temporal dynamic changes of land use.
\end{abstract}

\section{Introduction}

Land, the carrier of human activities, is one of the most important natural resources and offers physical space for human being to live in and carry out social, economic, and political activities. Land use/cover change (LUCC) is a key basis for studying natural resource management, climate change [1-4], and urban planning and also a major impact factor for environmental assessment $[5,6]$. It is closely connected with population migration and economic activities [7]. LUCC, therefore, has been a heated topic for geoscience [8] and also a core subject cosupported by International Geosphere Biosphere Programme (IGBP) and International Human Dimensions Programme (IHDP). The high precision land use dynamic change detection can provide basic data for the research of interaction relationship between human being and the nature [9-13].

Entering the 21st century, all regions have been experiencing rapid LUCC as the scope of human activities expands and land use intensity grows on a continuous basis $[14,15]$. Detection of dynamic change features and hotspots for land use is of great significance. That is how land resource can be better managed and used efficiently in the long run. At the same time, it also offers basic data for the study of human-nature interaction. For this reason, LUCC research of varying spatial scales has drawn wide attention at home and abroad [16-25].

Today, most research efforts focus on the process and driving mechanism of land use change and how land use change influences and feeds back to ecology and environment [26-28]. The research scale ranges from the globe to regions, and the researchers have obtained plentiful research achievement over the years [29-35]. Hotspots detection is an important research method to discover the active regions of regional development [36]. It can help to highlight regions sensitive to land use change, which is of critical importance for authorities, such as land and resources administration and urban planning department, to set up future land use strategy. For the time being, the research on land use change 
seldom involves hotspots detecting [37-42]; furthermore, no attention has been paid to the Beijing-Tianjin-Hebei Region in China. At the same time, land use research on the BeijingTianjin-Hebei Region rarely analyzes the process and driving factors of land use change in detail.

The main research methods of land use dynamic change in previous papers included land use dynamic index, transfer matrix, and driving force analysis. [17, 19, 26, 30-33]. Most of the previous researches were based on the land use classification map to calculate the intensity and scope of land use change, which rarely referred to spatial variation characteristics and hotspots analysis of land use dynamic change. The spatial transfer pattern of land use dynamic change was seldom mentioned, so the spatial evolution characteristics of regional land use dynamic change cannot be studied completely and deeply. In this article, from the perspective of spatial feature of land use dynamic change, the spatial characteristics of land use dynamic change were analyzed thoroughly using the map of land use transfer distribution, land use integrated dynamic index, the center of gravity of land use change and hotspots distribution of land use change on the basis of pervious researches. So, the research methods of this article were comprehensive and innovative in certain degree.

The Beijing-Tianjin-Hebei Region (Jing-Jin-Ji) is a core source for China's rapid economic growth. Particularly after 2000, this region has witnessed accelerating progress of urbanization and become a hotspot. However, the development level within the region varies greatly. The State Council of China has published Plan of Coordinated Development for the Beijing-Tianjin-Hebei to coordinate regional development and rearrange noncapital functions of Beijing. Under a structure of "One Core, Two Cities, Three Axes, Four Areas, and Multiple Nodes," the plan will promote order rearrangement of noncapital functions of Beijing and ultimately build a network space framework that combines major cities and functional zone platform of strategic importance. The "Four Areas" are, respectively, central core functional area [43-45], east coastal development area, south functional extension area, and northwest eco-conserving area. The central core functional area will be to undertake Beijing's noncapital functions and to accelerate the Beijing-TianjinBaoding interactive development. In the light of this, the central core functional area is key to Beijing-Tianjin-Hebei interactive development, in which land use strategy is a big question facing Beijing-Tianjin-Hebei land management department. This article follows the trend in LUCC research and answers to the demands by national key development planning strategy. Taking the central core functional area of Jing-Jin-Ji as the research object, this article utilized geographic information and geostatistics technologies, as well as classification data of remote sensing. Based on the spatial grid, the dynamic change characteristics of land use were analyzed to explore hotspots of land use change and their spatial relationships, and main driving factors of land use change are obtained in this article. It offers scientific basis and decision-making reference for the making of the land use policies, the rational use of land resources, and the optimization of land use structure, to better undertake Beijing's noncapital functions in the central core functional area.

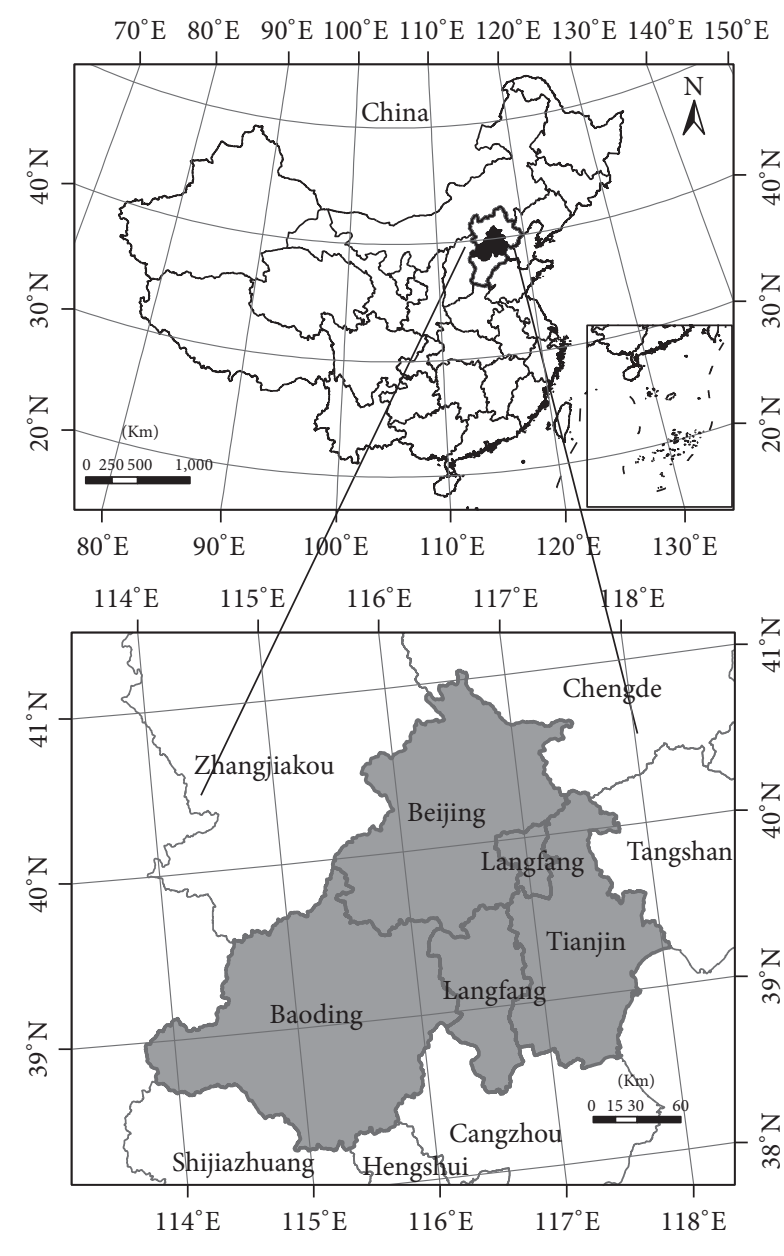

FIgURE 1: Location map of study area.

\section{Study Area and Data Sources}

The Jing-Jin-Ji region $\left(113^{\circ} 11^{\prime} \mathrm{E}-119^{\circ} 45^{\prime} \mathrm{E}, 36^{\circ} 05^{\prime} \mathrm{N}-42^{\circ} 37^{\prime} \mathrm{N}\right)$, shown in Figure 1, covers an area of $218,000 \mathrm{~km}^{2}$, about $2.27 \%$ of China. The region is located in North China Plain, Yanshan-Taihang Mountains, and the southeast side of Inner Mongolian Plateau. The region has mountains, hills, and plateaus in the northwest and broad plains in the middle and southeast, with the northwest part being higher than southeast part. The region has a typical continental monsoon climate with dry cold winter and hot rainy summer. The monthly average temperature is below $3^{\circ} \mathrm{C}$, with the average temperature in July between $18^{\circ} \mathrm{C}$ and $27^{\circ} \mathrm{C}$. The average annual precipitation is $524.4 \mathrm{~mm}$ [46]. The central core functional area of Jing-Jin-Ji includes Beijing, Tianjin as well as Baoding, and Langfang bordering Beijing and Tianjin. The central core functional area occupies an area of $57,000 \mathrm{~km}^{2}$, about $27 \%$ of Beijing-Tianjin-Hebei Region, with a population of 52,706,000 (2015) or a population density of 924 people $/ \mathrm{km}^{2}$. In 2015, the area registered a GDP of 4.24 trillion yuan, becoming more developed than other areas in the region. Population aggregation effect is obvious, especially in Beijing and Tianjin. Arable land and forest land are two major land use categories in the target area; the area 
of urban land expands very rapidly. In the background of regional coordinated development of Jing-Jin-Ji, Tianjin, Baoding, and Langfang will gradually undertake industrial transfer in Beijing, urban land and other construction lands will continue to expand, and land use structure will experience drastic changes. Given limited unused land in the region, making good use of land reserves will be a major direction for land development.

The research chose land use data and socioeconomic statistic data for analysis. The classification data of land use (30 m resolution) was provided by the Data Center for Resources and Environmental Sciences, Chinese Academy of Sciences (RESDC) in 2000, 2005, 2010, and 2015. The land use database was acquired by the rapid extraction of humancomputer interaction based on remote sensing spectrum information. The Landsat TM images were interpreted to build the $30 \mathrm{~m}$ resolution land use database covering the whole of China from 2000 to 2015 . While the Landsat TM data could not cover the whole of China or the quality of TM images was poor, the CCD multispectral data of $\mathrm{HJ}-1$ could be as a supplement $[47,48]$. In order to ensure the quality and consistency of data acquisition, the researchers examined the quality of each data and the process of data integration. Before the early development of land use database, the field investigation would be carried out to access to a large number of field investigation records and photos in the autumn of the north or in the spring of the south in China. The proportion of $10 \%$ counties of China were randomly selected to carry out accuracy verification of land use database. The accuracy of the comprehensive evaluation of land use type was more than $94.3 \%$, which met the user mapping accuracy of $30 \mathrm{~m}$ resolution [47, 49].

The data, with the accuracy over $90 \%$, met requirements for land use change analysis [49-51]. Based on IGBP LUCC and the research objective, a land use classification system (Tier I) was adopted. The system included 6 categories: arable land, forest land, grassland, water body, built-up land, and unused land. To increase understanding of regional land use characteristics, field investigations and interviews were also conducted in cities like Beijing, Tianjin, and Langfang. Socioeconomic statistic data were collected from China Social Economic Statistical Yearbook (2015) to discuss human factors driving land use change in the target area.

\section{Research Method}

This study adopted single dynamic index of land use, integrated dynamic index of land use, and land use transfer matrix to measure the temporal and spatial change characteristics of land use. The single dynamic index of land use can quantitatively be used to describe the change speed of regional land use $[52,53]$, which played an important role in comparing the regional differences of land use change and analyzing the change trend of land use [54]; the formula is

$$
K=\frac{u_{b}-u_{a}}{u_{a}} \times \frac{1}{T} \times 100 \% .
$$

In this formula, $u_{b}, u_{a}$ are the area of a certain land use category at the end and beginning moment of the research, respectively, and $T$ is length of the research period.

The integrated dynamic index of land use is the transfer rate among land categories during the research period [55], and it can reflect the overall change of all land categories in the study area during the research period $[56,57]$; the formula is

$$
K_{\text {total }}=\frac{\sum_{i=1}^{n}\left|u_{b i}-u_{a i}\right|}{2 \sum_{i=1}^{n} u_{a i}} \times \frac{1}{T} \times 100 \% .
$$

In this equation, $u_{b i}$ and $u_{a i}$ are the area of a certain land use category at the end and beginning moment of the research, respectively, $T$ is the duration of the study, and $n$ is the quantity of land use categories and is equal to 6 in this study. When $T$ is year(s), $K_{\text {total }}$ is the annual integrated change rate of area change of all land use categories.

The land use transfer matrix can reveal the land use structure at a certain point in time and quantitatively describe the dynamic process of the mutual transformation between land categories at the end and beginning of the research period and show the transferred-in and transferred-out information of each land category [58]. Based on the land use data of the research area in three time periods and four time points from 2000 to 2015, with the support of relevant spatial analysis modules of ArcGIS10.3 and ENVI5.3, this article conducted spatial analysis and statistics of the land use data of four periods to obtain the transfer matrixes of land use in three time periods, namely, 2000-2005, 2005-2010, and 2010-2015, and then contrasted the quantity and structural characteristics of land use change during 15 years. At the same time, the spatial distribution maps of land use transfer were obtained in three time periods by ENVI 5.3 postclassification processing module to analyze the spatial variation and features of land use transfer and explore the active regions of land use change during 15 years in the research region.

The center of gravity is the average $x$ - and $y$-coordinate of all the features in the study area. It is useful for tracking changes in the distribution or for comparing the distributions of different types of features. The center of gravity is given as

$$
\begin{aligned}
& X=\frac{\sum_{i=1}^{n} x_{i}}{n}, \\
& Y=\frac{\sum_{i=1}^{n} y_{i}}{n} .
\end{aligned}
$$

In the equation, $x_{i}$ and $y_{i}$ are the coordinate for feature $i$ and $n$ is equal to the total number of features.

The Weighted center of gravity extends to the following:

$$
\begin{aligned}
X_{w} & =\frac{\sum_{i=1}^{n} w_{i} x_{i}}{\sum_{i=1}^{n} w_{i}}, \\
Y_{W} & =\frac{\sum_{i=1}^{n} w_{i} y_{i}}{\sum_{i=1}^{n} \sum_{i=1}^{n} w_{i}} .
\end{aligned}
$$

In the equation, $w_{i}$ is the weight at feature $i$.

Hierarchical hotspot detection is one of the global clustering test methods, which is used to determine if there is 
clustering in the studied area and obtain the hotspots in a "Pyramid" type multilayer space based on a certain rule [58]. In the process of hierarchical hotspot detection, the "limit distance" of a "cluster unit" is defined and compared with the distance of spot pair in each space. When it is less than the limit distance, this spot will be included in the cluster unit $[37,39,58,59]$. The method of Nearest Neighbor Hierarchical Clustering is used to cluster the hotspots of land dynamic change; the main calculation formula is as follows.

The mean random distance was defined as

$$
d_{\mathrm{NN}(\mathrm{ran})}=0.5 \sqrt{\frac{A}{N}} .
$$

In the equation, $A$ is the area of the region and $N$ is the number of incidents and the standard error of the mean random distance is

$$
\mathrm{SE}_{d(\mathrm{ran})} \cong \sqrt{\frac{(4-\pi) A}{4 \pi N^{2}}}=\frac{0.26136}{\sqrt{N^{2} / A}} .
$$

In the equation, $A$ is the area of the region and $N$ is the sample size (number of incidents). The confidence interval around that distance is defined as

$$
\text { Confidence interval }=d_{\mathrm{NN}(\mathrm{ran})} \pm t * \mathrm{SE}_{d(\mathrm{ran})} \text {. }
$$

In the equation, $t$ is the $t$-value associated with a probability level in Student's $t$-distribution.

The approximate lower limit of this confident interval is

lower limit of confidence interval

$$
=d_{\mathrm{NN}(\mathrm{ran})}-t * \mathrm{SE}_{d(\mathrm{ran})} \cong 0.5 \sqrt{\frac{A}{N}}-t \sqrt{\frac{(4-\pi) A}{4 \pi N^{2}}}
$$

and the upper limit of this confidence interval is

upper limit of confidence interval

$$
=d_{\mathrm{NN}(\mathrm{ran})}+t * \mathrm{SE}_{d(\mathrm{ran})} \cong 0.5 \sqrt{\frac{A}{N}}+t \sqrt{\frac{(4-\pi) A}{4 \pi N^{2}}} .
$$

The confidence interval defines a probability for the distance between any pair of points.

For hierarchical clustering analysis, the number of spots in the cluster unit is specified to strengthen the clustering rules of elements. In this article, the "limit distance" was set to $30 \mathrm{~km}$ and the number of spots in the cluster unit was defined as 5 according to many tests. It also needed to provide a grid of the research region and determine the size of grid according to the accuracy and completeness of land use change, which, therefore, needed to be determined by repeated tests. The research region was eventually divided into 189 grids with the size of $20 \mathrm{~km} \times 20 \mathrm{~km}$ by reference to other researchers' research results $[37,39,60,61]$. The integrated dynamic index and the center of gravity of the integrated dynamic index of land use of each grid were, respectively, calculated in ArcGIS. The hotspots of land use dynamic change of the research region in three different time periods from 2000 to 2015 were obtained by use of the hotspots detection tool in Crimestat software (Crimestat 5.2), which were combined with other data to analyze the causes of formation of land use hotspots.

The center of gravity and hotspots analysis both can reflect the dynamic change tendency of land use intensity. The difference is that the gravity is the core point of dynamic change of regional land use, while the hotspots analysis reveals the core regions of land use dynamic change. At some point, there is only one point of gravity, but the one or several hotspots regions can be obtained from hotspots analysis. In general, gravity analysis can be used to analyze the transfer trend of regional land use dynamic change, which can reflect the transfer process of land use dynamic change intensity. The hotspots analysis can determine where land use change is more severe during the research period. The combination of two methods can be used to reflect the transfer characteristic of land use dynamic change intensity and also to obtain the hotspots regions of land use change.

\section{Research Results and Analysis}

4.1. Analysis of Land Use Quantity and Spatial Characteristics in Central Core Functional Area of Jing-Jin-Ji. Based on the land use spatial classification data of the four periods in the research region, the spatial distribution map of land use in different periods was produced (Figure 2), and the statistical tables of land use in the corresponding years (Table 1) were also produced to analyze the quantitative and spatial characteristics of land use changes. It can be seen that the main land categories were arable land, forest land, and builtup land, among which, the arable land was the largest, mainly distributed in the eastern and southern plains of the research region, including the southeastern part of Beijing, Langfang, northern and southern parts of Tianjin, and eastern part of Baoding, which was mainly distributed in rural settlements and around the city, with a great degree of fragmentation. The area of arable land accounts for over $45 \%$ of the total area of the studied area, but the arable land was decreasing gradually from about $50 \%$ in 2000 to $45 \%$ in 2015 , a decrease of nearly $5 \%$ and a significant decline in the quantity of arable land. This was mainly due to the rapid expansion of urban areas, especially around the main urban areas of Beijing and Tianjin, where part of the arable land was occupied.

The forest land was mainly distributed in the northwest mountain area of the research region, including the northwest part of Beijing and the western part of Baoding, with a concentrated contiguous distribution and small degree of fragmentation. From 2000 to 2015, the area of forest land was relatively stable and had less fluctuation, accounting for about $20 \%$ of the total area, which was mainly related to the national policy of the Closed Forest Project in China. In order to prevent dust weather, many State-Level Greening Projects have been started in the mountain area of Hebei, Beijing, and other places since the 1980s, which have been basically completed by 2000. In order to ensure the quality of The Shelter Forests, the state strictly limited changes of forest land, making the forest land area relatively stable.

Although the area of built-up land was less than that of arable land and forest land, the relative change was more 

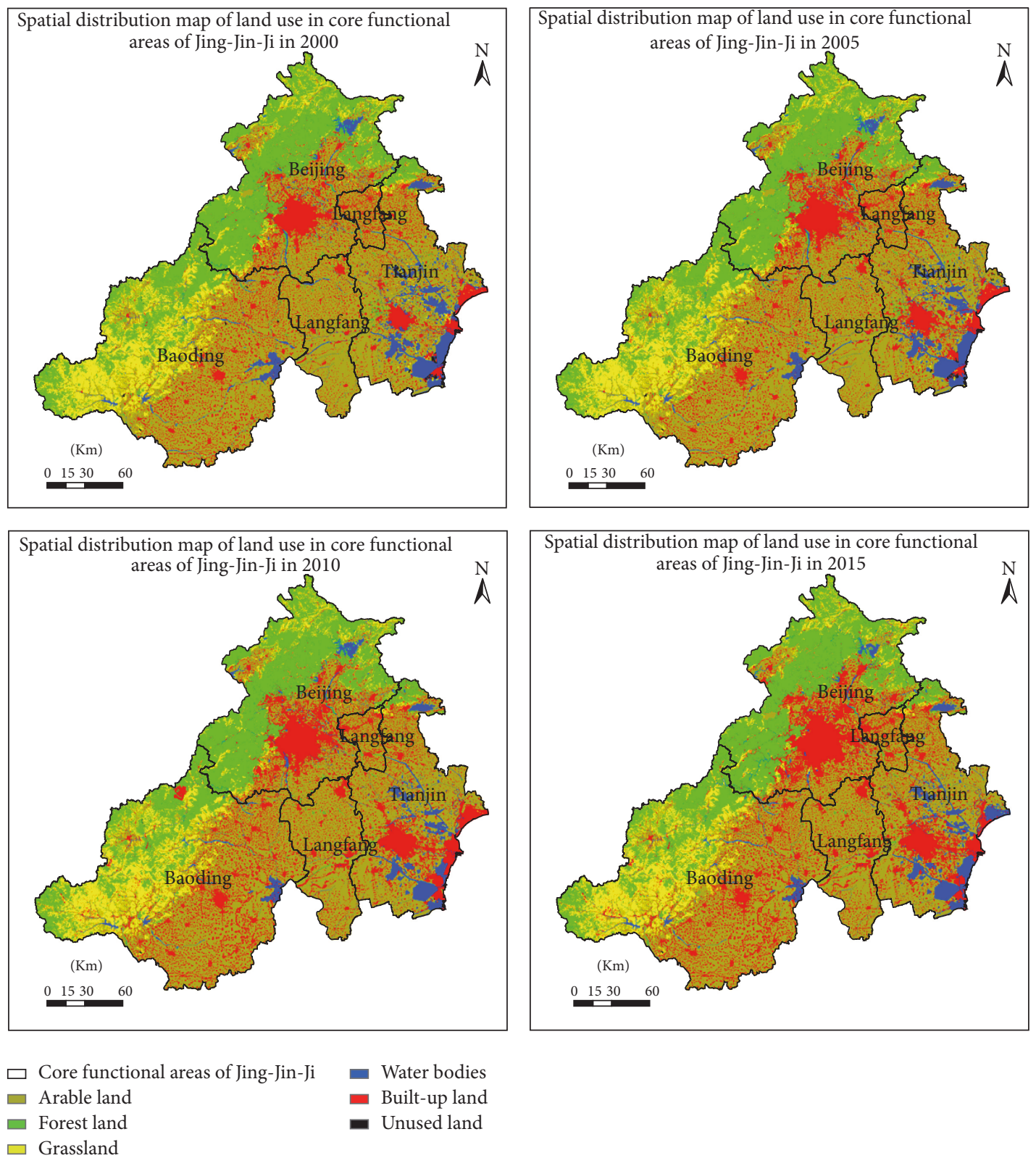

FIgURE 2: Spatial distribution map of land use in central core functional area of Jing-Jin-Ji from 2000 to 2015.

TABLE 1: Land use type structure in central core functional area of Jing-Jin-Ji.

\begin{tabular}{|c|c|c|c|c|c|}
\hline Land category & & 2000 & 2005 & 2010 & 2015 \\
\hline \multirow{2}{*}{ Arable land } & Area $\left(\mathrm{km}^{2}\right)$ & 27964.13 & 27300.68 & 26496.46 & 25612.27 \\
\hline & Proportion (\%) & 49.39 & 48.22 & 46.80 & 45.24 \\
\hline \multirow{2}{*}{ Forest land } & Area $\left(\mathrm{km}^{2}\right)$ & 11761.77 & 11731.70 & 11547.78 & 11520.04 \\
\hline & Proportion (\%) & 20.77 & 20.72 & 20.40 & 20.35 \\
\hline \multirow{2}{*}{ Grass land } & Area $\left(\mathrm{km}^{2}\right)$ & 6638.89 & 6593.44 & 6340.99 & 6135.64 \\
\hline & Proportion (\%) & 11.73 & 11.65 & 11.20 & 10.84 \\
\hline \multirow{2}{*}{ Water body } & Area $\left(\mathrm{km}^{2}\right)$ & 3160.18 & 2942.69 & 2440.62 & 2644.09 \\
\hline & Proportion (\%) & 5.58 & 5.20 & 4.31 & 4.67 \\
\hline \multirow{2}{*}{ Built-up land } & Area $\left(\mathrm{km}^{2}\right)$ & 6987.65 & 7963.80 & 9774.07 & 10688.97 \\
\hline & Proportion (\%) & 12.34 & 14.07 & 17.26 & 18.88 \\
\hline \multirow{2}{*}{ Unused land } & Area $\left(\mathrm{km}^{2}\right)$ & 102.68 & 82.97 & 13.28 & 12.77 \\
\hline & Proportion (\%) & 0.18 & 0.15 & 0.02 & 0.02 \\
\hline
\end{tabular}


intense, with an increasing trend year by year from 2000 to 2015 . From the space viewpoint, this type of land was mainly distributed in the plain area of the studied area, and the expanded region was mainly in the surrounding area of the original built-up land. The southern area of the main urban area of Beijing, the surrounding area of the main Tianjin urban area, and Binhai New Area were the regions expanding faster than other areas. In terms of quantity, the area of builtup land accounted for less than $20 \%$ of the regional area and showed a rapid increasing trend year by year, from $12.34 \%$ in 2000 to $18.88 \%$ in 2015 , an increase of nearly $6.5 \%$. There was the most rapid increasing area in all the land categories, reflecting the rapid urbanization in the past 15 years.

\subsection{Analysis of Land Use Transfer Features of the Central Core Functional Area of Jing-Jin-Ji}

4.2.1. Analysis of Quantity and Structural Characteristics of Land Use Transfer. The land use transfer matrix in the studied region in periods of 2000-2005, 2005-2010, 2010-2015, and 2000-2015 was shown in Tables 2-5. As shown in Tables 2-5, the main land category transferred from arable land during 2000-2005 was built-up land, with an area of $806.65 \mathrm{~km}^{2}$, accounting for about 3\% of the arable land area in 2000, and the main transferred-in land category was water area, with an area of $154.34 \mathrm{~km}^{2}$. In 2005-2010, there were no changes in the categories of transferred-out land, but the transferredout area increased rapidly, which amounted to $2,038.14 \mathrm{~km}^{2}$, with an increase of nearly 2.5 times, accounting for $7 \%$ of the arable land area in 2005, and the main transferred-in land categories were built-up land and water area, and about $3 \%$ of the land was transferred from built-up land. In 2010-2015, the main categories of transferred-out land did not change, but the transferred-out area decreased to $1,390.92 \mathrm{~km}^{2}$, reaching a decrease of about $31 \%$, accounting for $5.2 \%$ of the arable area in 2010, and the main transferred-in land categories were built-up land and forest land. Overall, from 2000 to 2015, the main transferred-out land categories from arable land were built-up land, and the main transferred-in land categories were built-up land, water body, and forest land, but the transferred-out area was far more than the transferred-in area, so the area of arable land was decreasing year by year. It can be seen that most of the transferred-out arable land was transferred into built-up land, which supported the need of economic development in this area.

In 2000-2005, the area of transferred-in and transferredout from forest land was relatively small, and the forest land was relatively stable. The main transferred-out land categories from 2005 to 2010 were built-up land and arable land, accounting for $2.4 \%$ of the total forest land area in 2005. The transferred-in land categories were arable land and water body, with a relatively small area. During 2010-2015, the main transferred-out land categories were arable land and builtup land, accounting for $3.5 \%$ of the total area of forest land in 2010, and the main transferred-in land categories were arable land and grassland, with less differences of transferredin area and transferred-out area. Therefore, from 2000 to 2015 , the area of forest land was relatively stable, with less transferred-in and transferred-out area. The land categories used to make up for the loss of forest land were arable land and grassland.

The transferred-out area from built-up land in 2000-2005 was small, with only $24.7 \mathrm{~km}^{2}$, but the transferred-out area was $1,000 \mathrm{~km}^{2}$. The transferred-in land categories were mainly arable land and water body, of which the arable land accounted for $80 \%$ of transferred-in area, being the main source of increasing built-up land. During 2005 to 2010, the trend was obviously different from the previous stage. The transferred-out area increased significantly, and its land category was arable land, accounting for $10.3 \%$ of built-up land. Besides, the main transferred-in land category was also arable land, which increased significantly to about $2,038.14 \mathrm{~km}^{2}$, accounting for about $20 \%$ of the built-up land in 2010 . It indicated that the transfer between arable land and built-up land was frequent in this period, and the urbanization and arable land consolidation were carried out at the same time, but the area of built-up land increased more rapidly. During 2010 to 2015 , the speed of transferred-in and transferred-out land slowed down, the main transferred-out land categories were the arable land and water body, and the transferred-in land was still arable land, with the area of $1,390.92 \mathrm{~km}^{2}$. From 2000 to 2015, the area of built-up land increased significantly. The main transferred-out land categories were the arable land and water body, and the main transferred-in land categories were the arable land, forest land, grassland, and water body, indicating that the most active land categories of the research region were the arable land and built-up land. The mutual conversion between them led to the increase of built-up land and the decrease of other land categories, especially the arable land, reflecting the drastic urbanization of the research region.

Grassland, water body, and unused land had less transferred-in and transferred-out area, and the trends in the three periods were very similar.

The transferred-out land category from grassland was mainly built-up land, and its main transferred-in land category was arable land. The main transferred-in and transferred-out land categories of water body were both arable land. The main transferred-out land categories of unused land were arable land and built-up land, and the transferred-out area was relatively less.

From the above statistics, the arable land and built-up land were the most active land categories. When other land categories changed, most of them were exchanged with these two land categories, which were mainly transferred-out area, relating to the speed of regional economic development and the national policy of arable land protection. The area of forest land was relatively stable, and it had less interaction with other land categories. The change of water body was closely related to the arable land, which was mainly due to the convenient conversion between arable land and water area. That is to say, after the conversion of arable land into water body, it could be used for aquaculture and salt pond. When the farming efficiency declined, it was also easy for the farmers to transform the water body into arable land, and this conversion often occurred in farmland. The studied area was located in relatively developed region, so its unused land area 
TABLE 2: Transfer matrix of land use in central core functional area of Jing-Jin-Ji from 2000 to 2005, unit $\left(\mathrm{km}^{2}\right)$.

\begin{tabular}{|c|c|c|c|c|c|c|}
\hline \multirow{2}{*}{2000} & \multicolumn{6}{|c|}{2005} \\
\hline & Arable land & Forest land & Grass land & Water body & Built-up land & Unused land \\
\hline Arable land & 27111.26 & 15.53 & 2.47 & 28.21 & 806.65 & 0 \\
\hline Forest land & 9.28 & 11712.87 & 0.3 & 1.84 & 37.47 & 0 \\
\hline Grass land & 9.14 & 2.27 & 6579.75 & 9.63 & 38.09 & 0 \\
\hline Water body & 154.34 & 0.31 & 8.53 & 2894.69 & 102.04 & 0.26 \\
\hline Built-up land & 16.57 & 0.71 & 2.36 & 5.06 & 6962.94 & 0 \\
\hline Unused land & 0.08 & 0 & 0.02 & 3.27 & 16.61 & 82.7 \\
\hline
\end{tabular}

TABLE 3: Transfer matrix of land use in central core functional area of Jing-Jin-Ji from 2005 to 2010, unit $\left(\mathrm{km}^{2}\right)$.

\begin{tabular}{|c|c|c|c|c|c|c|}
\hline \multirow{2}{*}{2005} & \multicolumn{6}{|c|}{2010} \\
\hline & Arable land & Forest land & Grass land & Water body & Built-up land & Unused land \\
\hline Arable land & 24989.07 & 63.59 & 14.55 & 189.62 & 2038.14 & 1.29 \\
\hline Forest land & 148.18 & 11408.17 & 8.18 & 19.72 & 145.44 & 0 \\
\hline Grass land & 85.4 & 25.85 & 6297.12 & 19.39 & 163.14 & 1.9 \\
\hline Water body & 412.19 & 42.91 & 1.95 & 2144.7 & 339.3 & 0.56 \\
\hline Built-up land & 822.56 & 4.94 & 12 & 51.81 & 7071.5 & 0.28 \\
\hline Unused land & 35.83 & 0.04 & 6.42 & 15.13 & 16.28 & 9.23 \\
\hline
\end{tabular}

TABLE 4: Transfer matrix of land use in central core functional area of Jing-Jin-Ji from 2010 to 2015, unit $\left(\mathrm{km}^{2}\right)$.

\begin{tabular}{|c|c|c|c|c|c|c|}
\hline \multirow{2}{*}{2010} & \multicolumn{6}{|c|}{2015} \\
\hline & Arable land & Forest land & Grass land & Water body & Built-up land & Unused land \\
\hline Arable land & 24797 & 151.54 & 47.37 & 108.43 & 1390.92 & 1.2 \\
\hline Forest land & 252.74 & 11098.72 & 18.67 & 28.62 & 149.03 & 0 \\
\hline Grass land & 72.08 & 154.34 & 6035.11 & 9.72 & 69.72 & 0.02 \\
\hline Water body & 133.13 & 17.29 & 5.43 & 2195.42 & 89.35 & 0 \\
\hline Built-up land & 356.88 & 97.29 & 28.77 & 301.86 & 8989.7 & 0.13 \\
\hline Unused land & 0.45 & 0.85 & 0.28 & 0.03 & 0.24 & 11.43 \\
\hline
\end{tabular}

TABLE 5: Transfer matrix of land use in central core functional area of Jing-Jin-Ji from 2000 to 2015, unit $\left(\mathrm{km}^{2}\right)$.

\begin{tabular}{|c|c|c|c|c|c|c|}
\hline \multirow{2}{*}{2000} & \multicolumn{6}{|c|}{2015} \\
\hline & Arable land & Forest land & Grass land & Water body & Built-up land & Unused land \\
\hline Arable land & 23572.01 & 153.25 & 62.23 & 278.32 & 3891.41 & 2.48 \\
\hline Forest land & 333.78 & 11097.02 & 29.75 & 36.19 & 263.00 & 0.00 \\
\hline Grass land & 154.34 & 182.26 & 6001.50 & 40.62 & 257.61 & 1.92 \\
\hline Water body & 630.27 & 58.74 & 9.74 & 2079.10 & 380.82 & 0.43 \\
\hline Built-up land & 882.46 & 25.59 & 25.27 & 191.52 & 5862.11 & 0.05 \\
\hline Unused land & 36.20 & 0.89 & 6.39 & 17.96 & 33.29 & 7.87 \\
\hline
\end{tabular}

was relatively small, which was often used as arable land or built-up land.

4.2.2. Analysis of Spatial Pattern Distribution of Land Use Transfer. The spatial pattern distribution of land use transfer from 2000 to 2015 was shown in Figure 3. During the three periods, there were obvious spatial differences in the research region. In 2000-2005, the transferred land of the studied area was located around the main urban area of Beijing and Tianjin, with the arable land and water body converted to built-up land. From 2005 to 2010, the active area of land transfer was located in the southeastern region, especially Tianjin Binhai New Area, whose main categories of land transfer were built-up land transferred from the arable land and the water body. From 2010 to 2015, the active area of land transfer was located in the outskirts of the main urban area of Beijing, and the process of land transfer was that built-up land was transferred from other land categories. In short, from 2000 to 2015, the land use transfer area was located in the middle and southeast part and centered in the surrounding regions of main urban areas of Beijing, main urban area of Tianjin, Tianjin Binhai New Area, Langfang, and Baoding. 

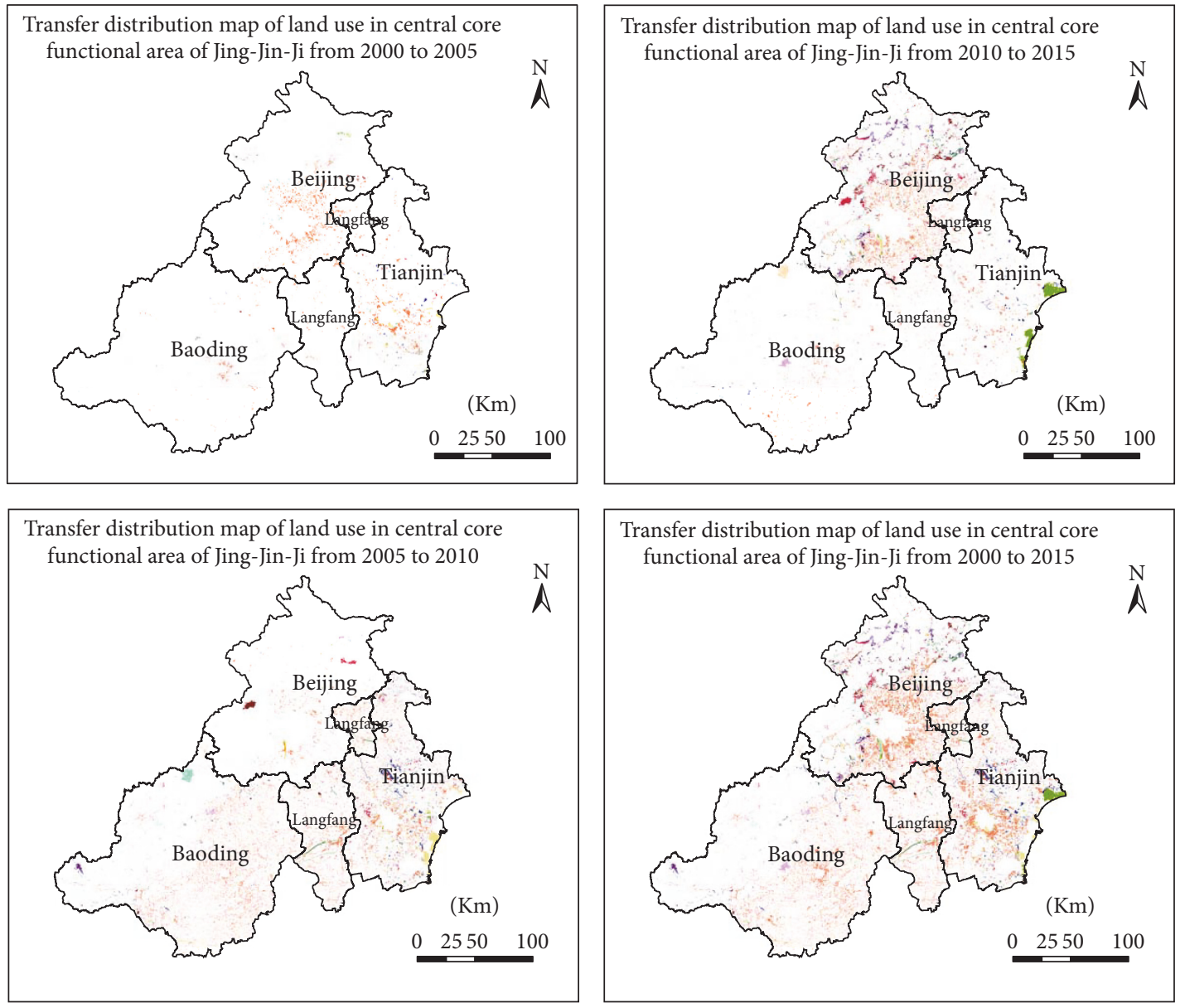

From arable land to built-up land

From forest land to built-up land

From grassland to built-up land

From water bodies to built-up land

From forest land to arable land

From built-up land to water bodies

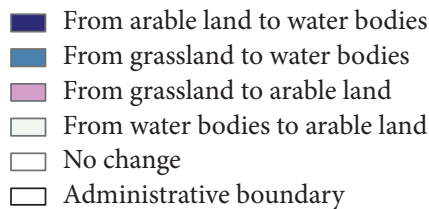

FIGURE 3: Transfer spatial map of land use in central core functional area of Jing-Jin-Ji from 2000 to 2015.

The main categories of land transfer were arable land and built-up land.

It can be seen that the land transfer regions of these three periods were closely linked with the economic development and National Policies of Jing-Jin-Ji. Beijing, as the key city in the central core functional area of Jing-Jin-Ji, has been developing rapidly since 2000 with the opportunity of hosting the Olympic Games, and its economic level and population scale have been expanding. But because of the single-center circle-mode urban planning, the size of the city kept expanding continuously. As shown in Figure 3, the active area of land transfer in Beijing continues to expand, which have expanded outwards beyond the sixth-ring road, reflecting the rapid expansion of Beijing's city size. The other land use categories have been rapidly transferred to builtup land. Tianjin Binhai New Area started to be planned into the National Development Strategy in 2005 and became the National New District with the key support of development and opening. Correspondingly, from 2005 to 2010, Tianjin Binhai New Area entered the high-speed development stage, promoting large-scale frequent land transfer. In the past 15 years, the land transfer scale of Baoding and Langfang has been relatively small, with the active areas mainly concentrated in the main urban area and the surrounding towns. There has not been a large-scale land transfer, providing a land space to undertake Beijing's noncapital function.

4.3. Analysis of Dynamic Change of Land Use in the Core Functional Area of Jing-Jin-Ji. According to formula (1), the single dynamic degree of the research region in 2000-2015 was calculated. As shown in Table 6, the largest single dynamic degree of land use in the studied area was the unused land in the former two periods, which was $-3.84 \%$ and $-16.8 \%$, respectively, indicating that the urban area developed rapidly in these two periods and occupied the unused land for economic activities, resulting in rapid depletion of unused 
TABLE 6: The single land use dynamic degree in central core functional area of Jing-Jin-Ji from 2000 to 2015.

\begin{tabular}{|c|c|c|c|c|c|c|c|c|}
\hline \multirow{2}{*}{ Land category } & \multicolumn{2}{|c|}{$2000-2005$} & \multicolumn{2}{|c|}{$2005-2010$} & \multicolumn{2}{|c|}{$2010-2015$} & \multicolumn{2}{|c|}{ 2000-2015 } \\
\hline & $\begin{array}{c}\text { Change } \\
\text { area }\left(\mathrm{km}^{2}\right)\end{array}$ & $\begin{array}{c}\text { Dynamic } \\
\text { degree }(\%)\end{array}$ & $\begin{array}{c}\text { Change } \\
\text { area }\left(\mathrm{km}^{2}\right)\end{array}$ & $\begin{array}{c}\text { Dynamic } \\
\text { degree (\%) }\end{array}$ & $\begin{array}{c}\text { Change } \\
\text { area }\left(\mathrm{km}^{2}\right)\end{array}$ & $\begin{array}{c}\text { Dynamic } \\
\text { degree }(\%)\end{array}$ & $\begin{array}{c}\text { Change } \\
\text { area }\left(\mathrm{km}^{2}\right)\end{array}$ & $\begin{array}{c}\text { Dynamic } \\
\text { degree }(\%)\end{array}$ \\
\hline Arable land & -663.46 & -0.47 & -804.21 & -0.59 & -884.19 & -0.67 & -2351.86 & -0.56 \\
\hline Forest land & -30.06 & -0.05 & -183.92 & -0.31 & -27.74 & -0.05 & -241.72 & -0.14 \\
\hline Grass land & -45.44 & -0.14 & -252.45 & -0.77 & -205.35 & -0.65 & -503.25 & -0.51 \\
\hline Water body & -217.48 & -1.38 & -502.07 & -3.41 & 203.47 & 1.67 & -516.09 & -1.09 \\
\hline Built-up land & 976.16 & 2.79 & 1810.27 & 4.55 & 914.90 & 1.87 & 3701.32 & 3.53 \\
\hline Unused land & -19.71 & -3.84 & -69.68 & -16.80 & -0.51 & -0.78 & -89.91 & -5.84 \\
\hline
\end{tabular}

land region and intense dynamic changes. In these two periods, the forest land had the lowest single dynamic degree of land use, only $-0.05 \%$ and $-0.31 \%$. Influenced by the national natural forest protection measures, the area of forest land was relatively stable and the dynamic change was less. In the period of 2010-2015, the built-up land had the largest single dynamic degree of land use, which was $1.87 \%$, followed by that of water body, which was $1.67 \%$. It means that the change trend of water body was different from that of the previous two periods. The dynamic degree changed from negative to positive indicated that the water area gradually increased in this period.

Overall, from 2000 to 2015, the unused land had the largest single dynamic degree of land use, up to $-5.84 \%$, followed by built-up land, which was $3.53 \%$. The dynamic change trends of these two land categories were on the contrary, indicating that, with the deepening of urbanization in the studied area, the unused land decreased sharply and the built-up land increased rapidly.

The changing tendency of single dynamic degree of land use showed that there were great differences of land categories in different periods. The dynamic degree of arable land and grassland was negative, the absolute value of which was increasing year by year (except for the dynamic degree of grassland in 2010-2015), indicating that the area of arable land and grassland decreased year by year, but the speed was increased. The dynamic degree of the forest land was relatively low, but the dynamic degree of the water body changed greatly, which was similar to dynamic degree of the arable land in the first two periods. The dynamic degree became positive, changing from annual decrease in the first two periods to annual increase in the third period, as shown in Figure 3. This was mainly because the original built-up land was transferred into water body in Tianjin Binhai New Area near Bohai Sea region, which might be related to the industrial policy and sea level changes. The changing trends of dynamic degree of built-up land and unused land were similar, showing the trend which is an increase first and later a decrease, but the change direction of the dynamic degree was opposite. The dynamic degree of unused land in 2005-2010 was over 4 times of that in 2000-2005, reflecting an acceleration of urbanization of the studied area and a rapid decrease of the unused land. Compared with situation between 2000-2005 and 2010-2015, the speed of urbanization

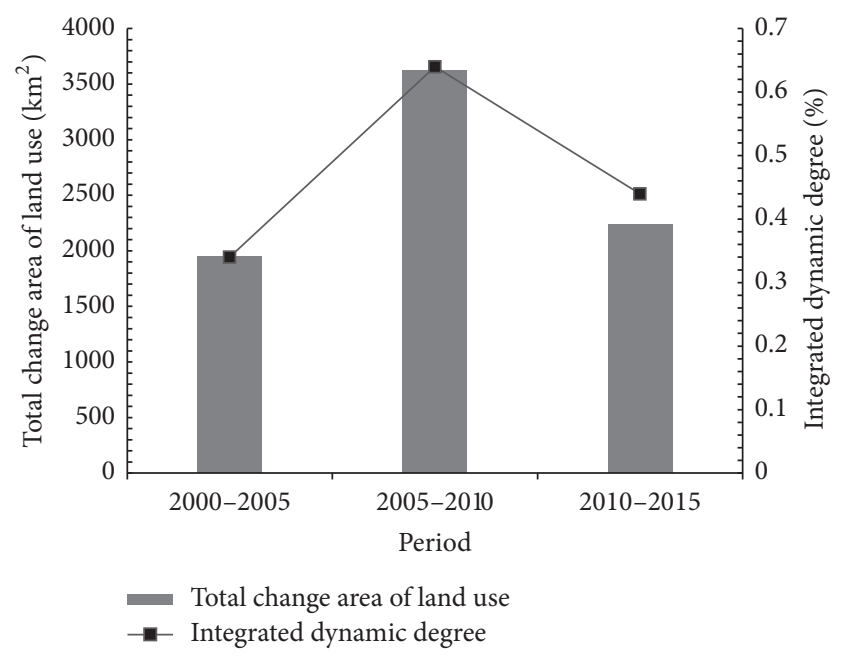

FIGURE 4: The change map of integrated dynamic degree of land use in central core functional area of Jing-Jin-Ji from 2000 to 2015.

construction was the fastest in 2005-2010, and the built-up land increased rapidly.

According to formula (2), the integrated dynamic degree of the studied area in 2000-2015 was calculated. As shown in Figure 4, the integrated dynamic degree of land use in 2005-2010 was $0.64 \%$, much higher than that in 2000-2005 and 2010-2015, which was nearly twice of the dynamic degree of land use in 2000-2005, indicating that the economic activity of the studied area was active and the conversion of land type was more frequent in this period. The total amplitude of land use change was similar to that in 2000-2005, which was about $2000 \mathrm{~km}^{2}$ in $2010-2015$. The integrated dynamic degree of land use was 30\% higher than that in 2000-2005, which indicated that the land transfer was more rapid in 2010-2015, and the land use change was more intense.

4.4. Analysis on Hotspot Area in Dynamic Change of Land Use in the Central Core Functional Area of Jing-Jin-Ji. In order to analyze the regional hotspots of land use dynamic change, the research region was divided into 189 grid regions, and the integrated dynamic degree of land use in every grid was calculated. Then, the spatial analysis tools of ArcGIS were used to produce the spatial distribution of integrated dynamic 


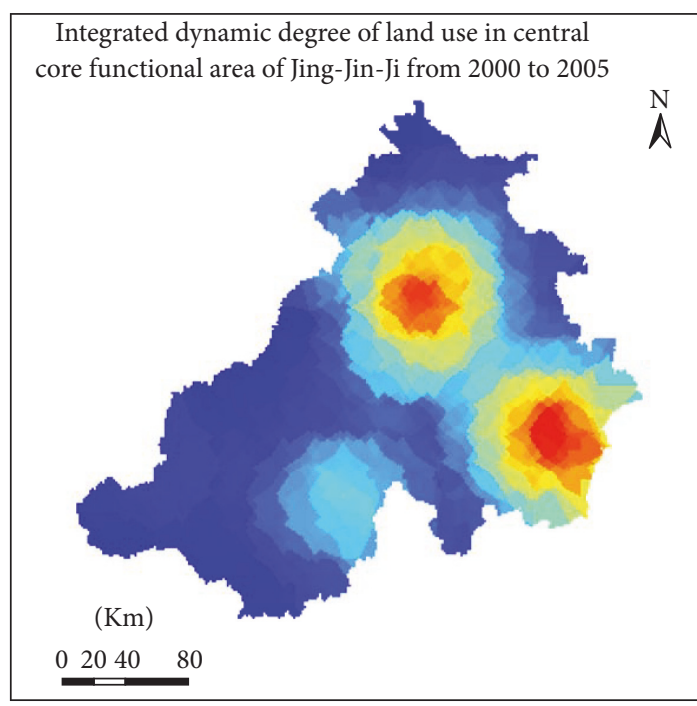

Integrated dynamic degree of land use Value High: 1.63

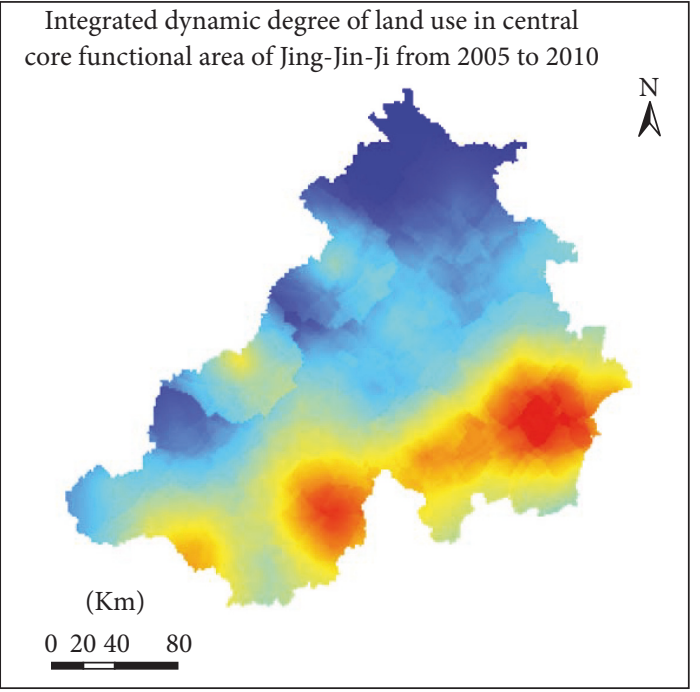

Integrated dynamic degree of land use Value

High: 1.77

0

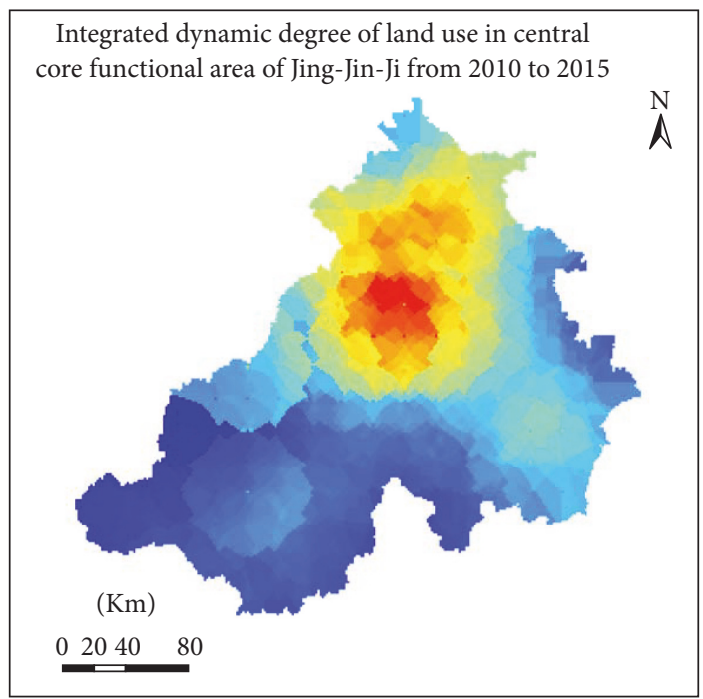

Integrated dynamic degree of land use

Value

High: 1.99
0.03

FIGURE 5: The spatial distribution map of integrated dynamic degree of land use in central core functional area of Jing-Jin-Ji from 2000 to 2015.

degree of land use in the studied area from 2000 to 2015 . As shown in Figure 5, there were significant spatial differences of dynamic degree of land use during the three research periods. In 2000-2005, the area with the larger dynamic change of land use was located in the central and eastern part of the studied area, and the western and northern areas were less varied. In 2005-2010, the dynamic change of land use was relatively average. Except for the small part regions in the northern and western, the dynamic changes of land use were great in most areas, especially the eastern and southern part. In 2010-2015, the regions with the larger dynamic change of land use were located in the north and the central regions.

The center of gravity analysis could be used to reflect the regional transfer of the integrated dynamic degree of land use over the three periods. Based on data of the 189 grids and ArcGIS spatial statistical tool, the center of 


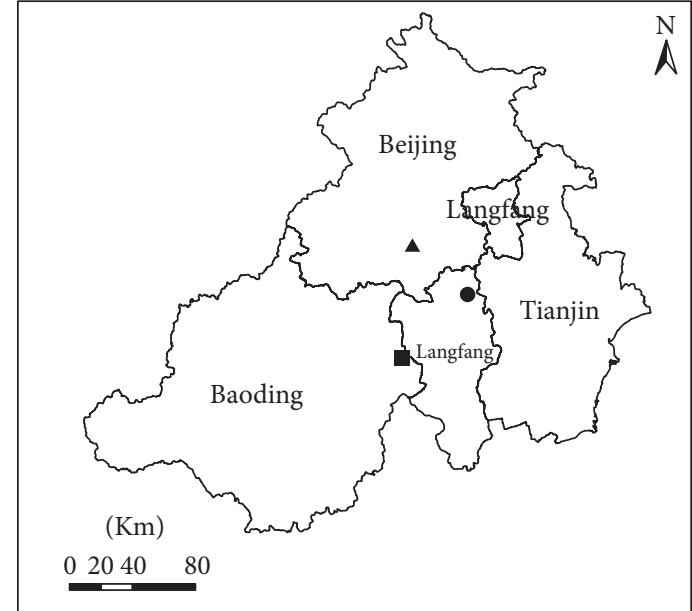

- Gravity center from 2000 to 2005

- Gravity center from 2005 to 2010

- Gravity center from 2010 to 2015

The central core functional area of Jing-Jin-Ji

FIGURE 6: The gravity center transfer spatial distribution map of integrated dynamic degree of land use in central core functional area of Jing-Jin-Ji from 2000 to 2015.

gravity change map in the research region was obtained in 2000-2015. As shown in Figure 6, the center of gravity of land use dynamic change was located in the central region of the studied area, which was close to the geometric center. The center of gravity of the three periods was located in north of Langfang, west of Langfang, and south of Beijing, respectively. In the first two periods, the center of gravity moved from northeast to southwest, reflecting the impetus of urbanization development to land use change in the southern region of the studied area, making the south region hotspots. In the third period, the center of gravity migrated from south to north, which reflected that the south of Beijing became the hotspots of land use dynamic change in the studied area.

In order to further identify the land use hotspots in the target area, the Crimestat 5.2 was used to carry out hotspots analysis on integrated dynamic degree of land use of 189 grids in the three periods, and hotspots distribution map was obtained, as shown in Figure 7. In 2000-2005, there were three land use hotspots, which were located around the main urban areas of Beijing, Tianjin, and Baoding, respectively. In 2005-2010, there were four hotspots, which were all located in the south of the research region, including Tianjin Binhai New Area, main urban area of Langfang, and south and west of Baoding downtown. In 2010-2015, the hotspots were mainly located in Beijing and the junction of Beijing-Tianjin. The hotspots obtained by Crimestat 5.2 was similar to that of spatial distribution map of integrated dynamic degree of land use, but more exact, which could mutually verify the accuracy of the land use hotspots in the studied area.

Transportation is the main driving force of land use change. With the improvement of regional traffic conditions, especially the construction of high-speed railway and expressway, the land use situation along the traffic can be

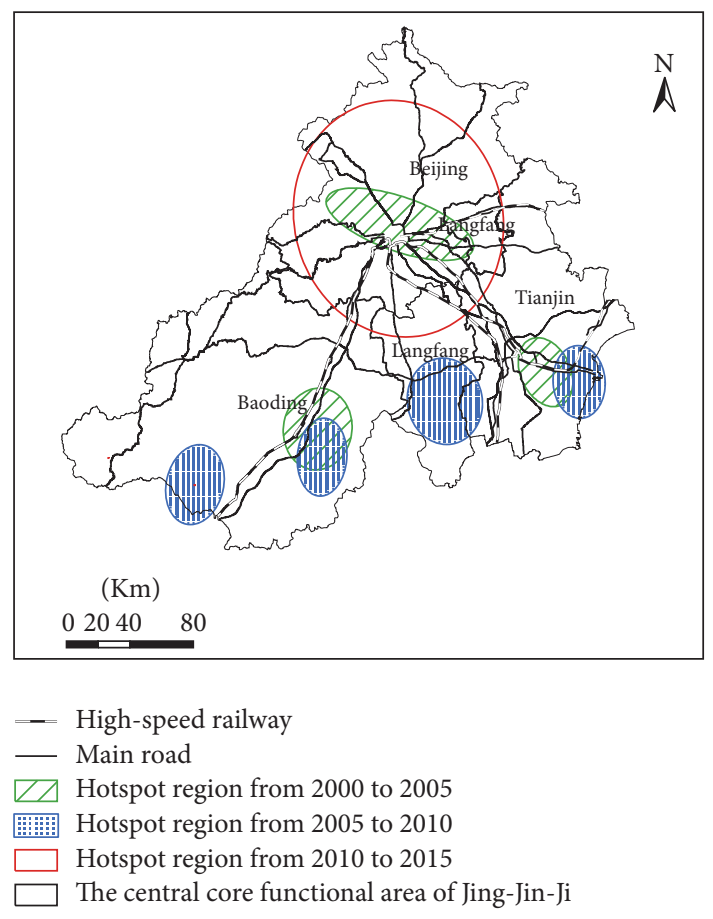

FIgURE 7: The hot spots map of dynamic changes of land use in central core functional area of Jing-Jin-Ji from 2000 to 2015.

changed, as shown in Figure 7. In 2000-2015, the hotspots of land use dynamic change in the research region were mainly distributed along the high-speed railway and expressway. Beijing had a unique traffic conditions because the country's major transport routes have been going through Beijing, so Beijing's land use hotspots were distributed along the traffic lines, with the main urban area of Beijing as the center. Tianjin's land use hotspots were located along the Jing-Jin intercity railway and the Jing-Jin expressway. The Beijing-Tianjin intercity railway was the earliest intercity railway in China. It has strengthened the economic links and population flows between Beijing and Tianjin and promoted land development along the road. The land use hotspots of Langfang were located between Beijing-Guangzhou Railway, G112, and Beijing-Fuzhou High-Speed Railway, with excellent traffic environment. The land use hotspots of Baoding were located along the Beijing-Zhuhai Expressway and BeijingShijiazhuang High-Speed Railway. The two traffic arteries went through the hotspots of the eastern side of Baoding. All of these indicated that the traffic was an important factor affecting the dynamic change of land use in the research region.

In addition to transportation, economy, population, and policy were also main reasons of the gravity transfer and hotspots migration of land use dynamic change. Beijing and Tianjin were the most developed areas in the research region. From 2000 to 2015, the GDP increased more than 3 times in Beijing and Tianjin (Figure 9). Economic development was bound to increase investment in fixed assets and related projects, which would accelerate regional land use change. The increase of population was also the reason for the land 
use dynamic change and formation of hotspots. Beijing, as the capital of China, has a huge attraction to the surrounding population. From 2000 to 2015, the population of Beijing has increased nearly 5 million, and Tianjin was also similar about population. So, the center of gravity transferred around the southern of Beijing and northern of Tianjin, and the hotspots of land use change were mainly concentrated in Beijing and Tianjin during the research period, especially 2000-2005 and 2010-2015.

National and regional development policies were also important factors in the hotspots formation of land use dynamic change. Since 2004, the Chinese government has formulated a series of policies and measures for the development of Jing-Jin-Ji, including Regional Planning of Jing-JinJi Metropolitan, Regional Planning of Beijing Capital Circle, Coordinated Development of Urban Planning of Jing-Jin-Ji, and Urban and Rural Spatial Development Planning of Jing-Jin$J i$. These policies put forward the development strategy of the research region, formulated the development direction, and accelerated the land use dynamic change to form some hotspots regions. For example, Beijing-Tianjin intercity highspeed railway has promoted the economic development of the Beijing-Tianjin corridor, including Fengtai in Beijing, Langfang in Hebei, and Wuqing in Tianjin. The development of Tianjin Binhai New Area has made the land use change rapidly, and capital new airport has made the regional land development change actively, such as Daxing in Beijing, Langfang in Hebei, and Wuqing in Tianjin.

\section{Conclusion and Discussion}

5.1. Conclusion. The central core functional area of JingJin-Ji is the key area of coordinated development of JingJin-Ji, which is also a hotspot region of land use dynamic change. This article analyzed the quantitative and spatial characteristics of land use dynamic change in the support of four periods of land use classification distribution map from 2000 to 2015, based on land use dynamic index, land use transfer matrix, and hotspots detection. The trend of land use dynamic change and the hotspots of land use change were also detected in the research area. The results showed that arable land was the largest area in the studied area, accounting for $45 \%$ of the total area, which was mainly distributed in the east and south of the research region, and the area of arable land decreased year by year from 2000 to 2015. The transferredout land was mainly used as built-up land. Forest land was the second largest area, which was intensively distributed in the northwest mountain area, and the area was basically stable. The built-up land was relatively active, the area of which increased rapidly with an increase of nearly $7 \%$. The main transferred-in land categories were arable land and water body. From the spatial distribution of land use transfer, the main area of land use transfer continuously switched from around the main urban area of Beijing and Tianjin in 2000-2005 to the southeast regions of the research area in 2005 to 2010 and then to suburb away from the main urban area of Beijing in 2010-2015.

In 2005-2010, there was the highest integrated dynamic degree of land use in the studied area, which was $0.64 \%$, much higher than that of 2000-2005 and 2010-2015, and was twice as high as integrated dynamic degree of land use in 2000-2005, showing that the land categories transformation was more frequently. The region with large integrated dynamic degree of land use in 2000-2005 was in the middle and east part of the research area, and there was less change on the west and north part of the research area. The center of gravity of land use of the research area transferred from northeast to southwest and then to north. In 2000-2005, there were three hotspots of land use dynamic change, which were located around the main urban areas of Beijing, Tianjin, and Baoding, respectively. In 2005-2010, there were four hotspots, which were all located in the south of the studied area, including Tianjin Binhai New Area, main urban area of Langfang, and south and west of Baoding downtown. In 2010-2015, the hotspots were mainly located in Beijing and the junction of Beijing-Tianjin. The area of the hotspots expanded gradually, reflecting the accelerating urbanization process in the research region.

In brief, the rapid decrease of arable land area and the sharp increase of built-up land area were the main characteristic of the dynamic change of land use in the research region. From 2000 to 2015, the net transferred-out area of arable land increased year by year and reached $884.63 \mathrm{~km}^{2}$ in 2010-2015, accounting for 3.5\% of the arable land in 2015. In 2000-2005, $790.08 \mathrm{~km}^{2}$ (net area) arable land (after deducting the area transferred from built-up land) transferred to built-up land, followed by $1,215.58 \mathrm{~km}^{2}$ and $1,034.04 \mathrm{~km}^{2}$ in the subsequent two periods. In 2005-2010, the net area of arable land accounted for $12 \%$ of built-up land. Since 2000 , the area of arable land has shown an irreversible decrease trend, which on one hand has met the demand of land for urban expansion but on the other hand has reduced the least cultivated areas and food security of the target area. China implements the fundamental policy of "requisitioncompensation balance." Therefore, the region should, on the premise of maintaining the existing farmland scale, improve the productivity of arable land, ensure the grain security, and protect the regional ecological environment.

In 2000-2010, the dynamic degree of land use increased, indicating that the intensity of land use change was increasing during this period, which reflected the impact of urbanization development on land use. With the constant deepening of people's attention to the ecological environment and the proposal of integrative development strategy for Jing-Jin-Ji, the government has carried out a series of land use planning and conducted reasonable planning of urban development in order to avoid waste and idling of land resources, which was the main reason for the decline of land use dynamic degree in 2010-2015.

In the research region, the intensity and area of hotspots in land use dynamic change increased, but the change range of the center of gravity was small. In terms of quantity, it covered the most land use hotspots in the period of 2005-2010, and there were 4 regions. In terms of area, there was the largest area of land use hotspots in the period of 2010-2015. The center of gravity transferred in the central region of the studied area. The hotspots analysis of land use could help to develop reasonable land use policy and realize rational 


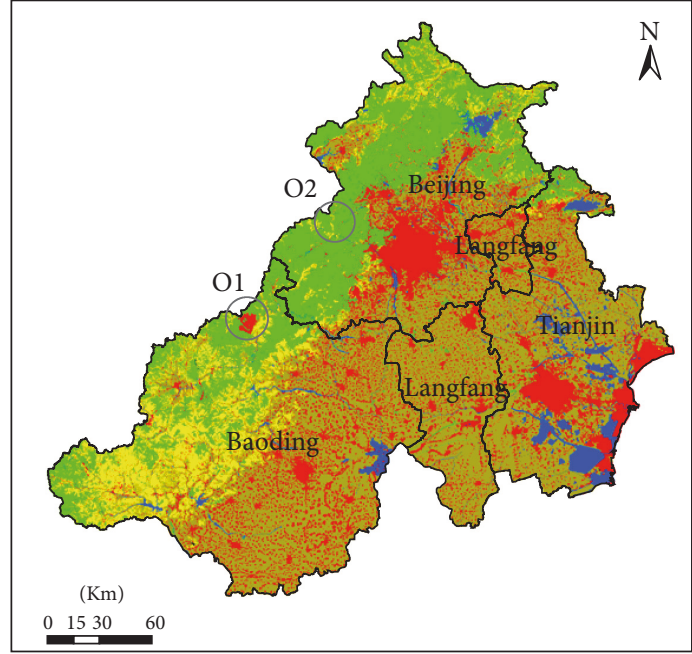

$\begin{array}{ll}\square \text { Core functional areas of Jing-Jin-Ji } & \text { Water bodies } \\ \square \text { Arable land } & \text { Built-up land } \\ \text { Forest land } & \text { Unused land }\end{array}$

Figure 8: The error classification map of land use in central core functional area of Jing-Jin-Ji in 2010.

exploitation and sustainable utilization of land resources in Jing-Jin-Ji.

\subsection{Discussion}

5.2.1. Land Use Data. The land use data used in this article comes from the Environmental Science Data Center of the Chinese Academy of Sciences. The accuracy of land use classification is as high as $94.3 \%$, which meets the research needs. However, since the classification accuracy is obtained at the national scale, there might exist differences for different research regions. According to test, the accuracy of land classification was relatively high in most of the research region. But as shown in Figure 8, part of the region was classified wrongly, which marked the wrongly classified regions with circles. In the land use classification map of 2010, O1 was classified into built-up land, and $\mathrm{O} 2$ was classified into forest land, while in the land use classification maps of the other three periods, $\mathrm{O} 1$ was forest land and $\mathrm{O} 2$ was arable land (Figure 2). These two regions were in the mountainous area of the northwest Jing-Jin-Ji, so it was impossible for them to change abruptly without large-scale man-made interference. The classification data was believed wrong initially. After looking into the high-resolution image (Google Earth) of the relevant location, it was confirmed that $\mathrm{O} 1$ and $\mathrm{O} 2$ were classified wrongly. Before analyzing land use transfer, dynamic degree, and hotspots, these two wrong classifications had been corrected.

5.2.2. Exploration Method of Active Regions of Land Use. According to the above study methods and conclusions, the spatial distribution of land use transfer, the spatial distribution of integrated dynamic degree of land use, and the exploration of land use hotspots have illustrated the active regions of land use change from the different views. The spatial distribution of land use transfer showed the regions and categories of land use transfer in the studied area. The spatial distribution of integrated dynamic degree of land use reflected the spatial variation characteristics of land use transfer speed. The exploration of hotspots of land use could obtain the hotspots of land use dynamic change. The results of these three analysis methods could be mutually verified to reflect the active regions of land use in the studied area.

5.2.3. Driving Force of Land Use Change. The central core functional area of Jing-Jin-Ji is the key area for Beijing to carry out noncapital function in Jing-Jin-Ji coordinated development. Since 2000, with the development of economy, land use category has changed greatly in each city but the development way was more extensive. After the coordinated development of Jing-Jin-Ji for the National Strategy, land use would develop with the direction of unified planning and scientific utilization. In the whole process, the human factor played a decisive role in the land use change. Therefore, when analyzing the driving force of land use change, it should start from the human factors, mainly including population, economics, and policy.

As one of three core engines of China's economic development, Jing-Jin-Ji region plays an important role in national economic system. The GDP and population size of the research region in 2000-2015 were shown in Figure 9, showing that economic gap between the studied areas was relatively large, of which economic levels of Beijing and Tianjin were much higher than those of Langfang and Baoding; however, the growth trend was basically the same. In 2000, economic level of each city started to grow rapidly with the average annual growth rate of about $10 \%$. The economics gap was prerequisite for the integration of Jing-Jin-Ji; it was possible to ease Beijing's noncapital function. Population size was also expanding, but with the restriction on population size of large cities, the average annual population growth showed stage characteristics. Compared to 2000-2005 and 2010-2015, it was the stage with rapid population growth in 2005-2010. Correspondingly, it had relatively high land use dynamic degree and the most hotspots in 2005-2010, which showed that population aggregation could promote the process of regional urbanization and significantly increase the area of built-up land.

From the policies point of view, on the one hand, some national and local ecological protection projects have been promulgated since 2000, mainly including Grain for Green Project, Sand Dust Source Control Project in Beijing and Tianjin, and Three North Forest Protection Project. These projects have promoted the protection of the ecological environment in Jing-Jin-Ji region, relatively stabilized the regional forest land area, and achieved a slight increase in some regions (such as Beijing). On the other hand, JingJin-Ji coordinated development has been developed into National Strategy, the issue of Outline of the Plan for JingJin-Ji Coordinated Development provided policy guidance for Jing-Jin-Ji coordinated development, and it would have more detailed polices introduced in the future. Land is the key 

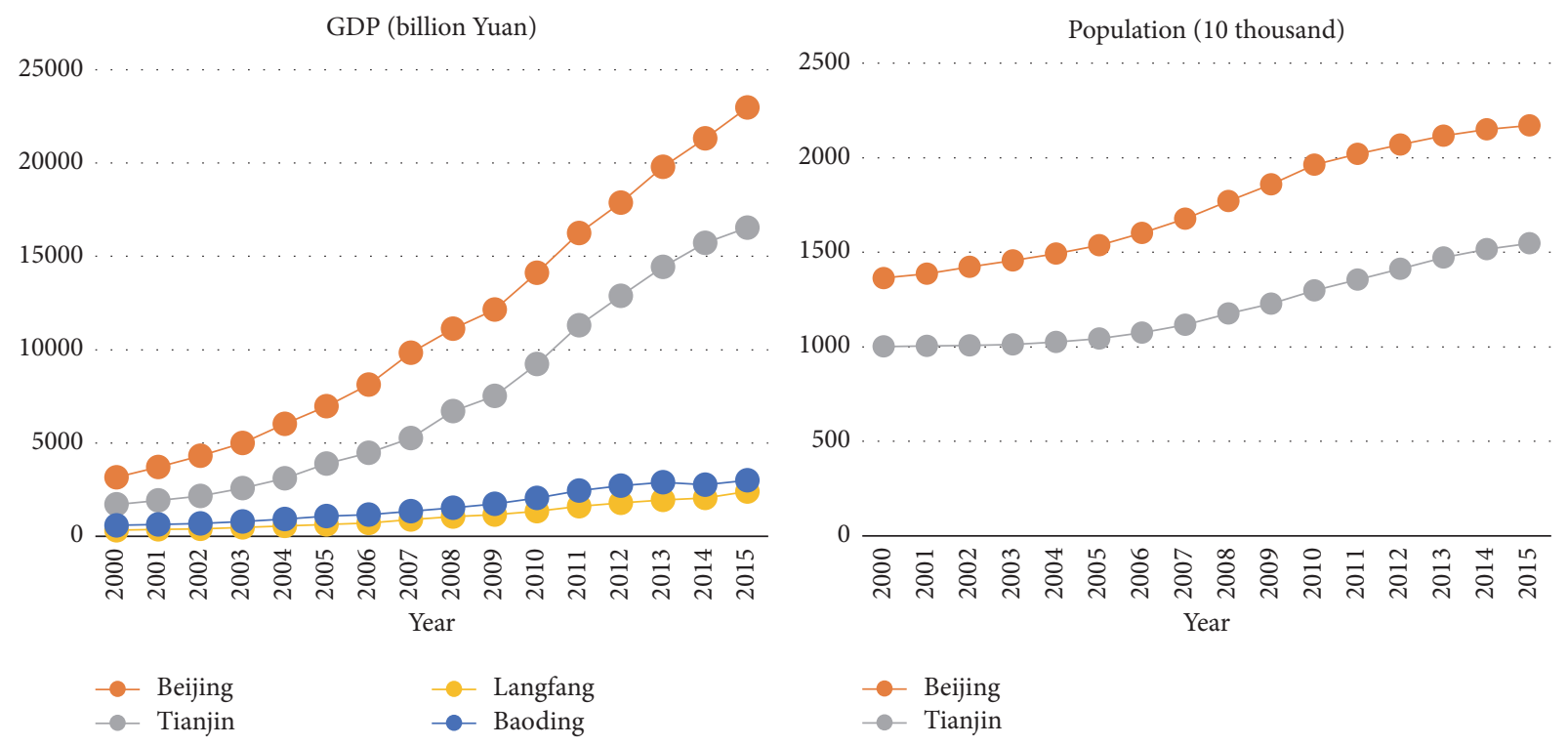

FIgURE 9: The change trend map of population and GDP in central core functional area of Jing-Jin-Ji from 2000 to 2015.

factor for Jing-Jin-Ji coordinated development, and how to utilize the land resources rationally and plan the quantity and distribution of each land category is the key to land policy. Therefore, the policies of Jing-Jin-Ji coordinated development would be also the important driving force of land use dynamic change in the future.

5.3. Outlook. The central core functional area of Jing-Jin-Ji takes the important responsibility of noncapital functions of Beijing. Both the outflow of industry and personnel need land resource as the carrier. To reasonably plan and comprehensively arrange the land resources of central core functional area of Jing-Jin-Ji is of great importance to the realization of Jing-Jin-Ji coordinated development. Therefore, research on land use status, dynamic change, and transfer characteristics of the research region provided decision reference for land use policies-making of this region, having great significance. In this article, the authors deeply researched the land use status and dynamic changes of the central core functional area of Jing-Jin-Ji; however, the mechanism and simulation of land use dynamic changes of the region were not involved. We will increase the prediction simulation of land use in the research region and set up different development scenarios to forecast the dynamic change characteristics of land use and hotspots in order to improve the support of policy-making departments in the future. In addition, the main data used in this research is the existing data of land use distribution. Remote sensing images can be used to update and validate land use data in the future.

Based on the results of this article, we can see that the level of land use was very uneven in the central core functional area of Jing-Jin-Ji. It is necessary to formulate some land policies which are suitable for the characteristics of regional land use change. The regional land use efficiency should be improved under the premise of protecting arable land. From the view of land use distribution, the built-up land was mainly concentrated in Beijing and Tianjin, which was expanding rapidly, especially Beijing (Figures 2 and 3). In the context of integration of Jing-Jin-Ji, the land management department should formulate land policies to restrict the expansion rate of built-up land in Beijing, control the increase of built-up land, and encourage the conversion of stock built-up land into ecological land. At the same time, the industries that need occupy the larger area land should be transferred to the other regions, such as Langfang and Baoding. From the point of view of hotspots of land use, the hotspots were located in the areas along the main road and supported by national policies, such as Binhai New Area (Figures 5 and 7). Therefore, in order to promote the balanced and efficient development of regional land use, the land management department should provide adequate land recourse for the transportation infrastructure to improve the regional accessibility, promote the development of industries along the traffic, and guide the reasonable population aggregation, so that we can achieve the purpose of easing Beijing's noncapital functions and promoting the coordinated development of Jing-Jin-Ji. Finally, when the departments formulate the land development strategies, it is important to focus on the regions in which land use changes severely (Figure 3). If necessary, the land management department should limit the rate of land use transfer in the violent area of land use change in order to ensure adequate reserve land.

\section{Conflicts of Interest}

The authors declare that there are no conflicts of interest regarding the publication of this paper.

\section{Acknowledgments}

This study was supported by the National Natural Science Foundation of China (41501430, U1633124, 41271546, and 
61603396) and Natural Science Foundation of Tianjin (Youth Project: Simulation of the Impact of Airport Construction on Regional Ecological Environment Change and Urbanization in Jing-Jin-Ji.)

\section{References}

[1] E. F. Lambin, H. J. Geist, and E. Lepers, "Dynamics of land-use and land-cover change in tropical regions," Annual Review of Environment and Resources, vol. 28, pp. 205-241, 2003.

[2] J. Feddema, K. Oleson, G. Bonan et al., "A comparison of a GCM response to historical anthropogenic land cover change and model sensitivity to uncertainty in present-day land cover representations," Climate Dynamics, vol. 25, no. 6, pp. 581-609, 2005.

[3] I. C. Bohnet, B. Roberts, E. Harding, and K. J. Haug, "A typology of graziers to inform a more targeted approach for developing natural resource management policies and agricultural extension programs," Land Use Policy, vol. 28, no. 3, pp. 629-637, 2011.

[4] Y. Tsai, A. Zia, C. Koliba, G. Bucini, J. Guilbert, and B. Beckage, "An interactive land use transition agent-based model (ILUTABM): endogenizing human-environment interactions in the Western Missisquoi Watershed," Land Use Policy, vol. 49, pp. 161-176, 2015.

[5] A. Wahid, Geo-Environmental Assessment and Landuse Planning for Coastal Plains, Lap Lambert Academic Publishing, 2011.

[6] M. Li, J. Wu, and X. Deng, "Land use change and soil carbon sequestration in China: where does it pay to conserve?" Regional Environmental Change, pp. 1-13, 2016.

[7] Y. Li, Y. Liu, H. Long, and W. Cui, "Community-based rural residential land consolidation and allocation can help to revitalize hollowed villages in traditional agricultural areas of China: Evidence from Dancheng County, Henan Province," Land Use Policy, vol. 39, pp. 188-198, 2014.

[8] X. B. Li, "A review of the international researches on land use/land cover change," Acta Geographica Sinica, vol. 6, pp. 553$558,1996$.

[9] N. C. Gautam and G. C. Chennaiah, "Land-use and landcover mapping and change detection in Tripura using satellite LANDSAT Data," International Journal of Remote Sensing, vol. 6, no. 3-4, pp. 517-528, 1985.

[10] Q. Weng, "Land use change analysis in the Zhujiang Delta of China using satellite remote sensing, GIS and stochastic modelling," Journal of Environmental Management, vol. 64, no. 3, pp. 273-284, 2002.

[11] H. J. König, J. Schuler, U. Suarma et al., "Assessing the impact of land use policy on urban-rural sustainability using the FoPIA approach in Yogyakarta, Indonesia," Sustainability, vol. 2, no. 7, pp. 1991-2009, 2010.

[12] K. Swangjang and V. Iamaram, "Change of land use patterns in the areas close to the airport development area and some implicating factors," Sustainability, vol. 3, no. 9, pp. 1517-1530, 2011.

[13] G. Sen, M. M. Bayramoglu, and D. Toksoy, "Spatiotemporal changes of land use patterns in high mountain areas of northeast turkey: a case study in maçka," Environmental Monitoring and Assessment, vol. 187, no. 8, article no. 515, pp. 1-14, 2015.

[14] M. Al-shalabi, B. Pradhan, L. Billa, S. Mansor, and O. F. Althuwaynee, "Manifestation of Remote Sensing Data in Modeling Urban Sprawl Using the SLEUTH Model and Brute Force Calibration: a Case Study of Sana'a City, Yemen," Journal of the
Indian Society of Remote Sensing, vol. 41, no. 2, pp. 405-416, 2013.

[15] S. L. Tuck, C. Winqvist, F. Mota, J. Ahnström, L. A. Turnbull, and J. Bengtsson, "Land-use intensity and the effects of organic farming on biodiversity: a hierarchical meta-analysis," Journal of Applied Ecology, vol. 51, no. 3, pp. 746-755, 2014.

[16] C. Su, B. Fu, Y. Lu et al., "Land use change and anthropogenic driving forces: a Case Study in Yanhe River Basin," Chinese Geographical Science, vol. 21, no. 5, pp. 587-599, 2011.

[17] K. Zhang, Z. Yu, X. Li, W. Zhou, and D. Zhang, "Land use change and land degradation in China from 1991 to 2001," Land Degradation and Development, vol. 18, no. 2, pp. 209-219, 2007.

[18] D. R. Thielen, J. J. San José, R. A. Montes, and R. Lairet, “Assessment of land use changes on woody cover and landscape fragmentation in the Orinoco savannas using fractal distributions," Ecological Indicators, vol. 8, no. 3, pp. 224-238, 2008.

[19] J. Y. Liu, W. H. Kuang, Z. X. Zhang et al., "Spatiotemporal characteristics, patterns and causes of land use changes in china since the late 1980s," Acta Geographica Sinica, vol. 69, pp. 3-14, 2014.

[20] R. E. Kennedy, P. A. Townsend, J. E. Gross et al., "Remote sensing change detection tools for natural resource managers: Understanding concepts and tradeoffs in the design of landscape monitoring projects," Remote Sensing of Environment, vol. 113, no. 7, pp. 1382-1396, 2009.

[21] Minakshi, R. Chaurasia, and P. K. Sharma, "Landuse/land cover mapping and change detection using satellite data-a case study of Dehlon block, district Ludhiana, Punjab," Journal of the Indian Society of Remote Sensing, vol. 27, no. 2, pp. 115-121, 1999.

[22] H. Chen, S. Yan, Z. Ye, H. Meng, and Y. Zhu, "Utilization of urban sewage sludge: Chinese perspectives," Environmental Science and Pollution Research, vol. 19, no. 5, pp. 1454-1463, 2012.

[23] M. R. Altaweel, L. N. Alessa, A. D. Kliskey, and C. E. Bone, "Monitoring land use: capturing change through an information fusion approach," Sustainability, vol. 2, no. 5, pp. 1182-1203, 2010.

[24] M. C. Hansen and T. R. Loveland, "A review of large area monitoring of land cover change using Landsat data," Remote Sensing of Environment, vol. 122, pp. 66-74, 2012.

[25] G. Han, J. Chen, C. He et al., "A web-based system for supporting global land cover data production," Journal of Photogrammetry \& Remote Sensing, vol. 103, pp. 66-80, 2015.

[26] C. Z. Li, F. L. Yu, J. Liu et al., "Research on land use/cover change and its driving force in midstream of the heihe mainstream basin during the past 20 years," Journal of Natural Resources, pp. 353-363, 2011.

[27] F. J. Gao, G. P. Lei, F. H. Yang et al., "Eco-security evaluation before and after Grain for green in project mudangjiang city," Transaction of the CSAE, vol. 28, pp. 206-214, 2012.

[28] Y. Y. Li, J. X. Chang, Y. M. Wang et al., "Spatiotemporal responses of runoff to land use change in wei river basin," Transaction of the CSAE, vol. 32, pp. 232-238, 2016.

[29] H. Delile, L. Schmitt, N. Jacob-Rousseau, L. Grosprêtre, G. Privolt, and F. Preusser, "Headwater valley response to climate and land use changes during the Little Ice Age in the Massif Central (Yzeron basin, France)," Geomorphology, vol. 257, pp. 179-197, 2016.

[30] J. Y. Liu, Z. X. Zhang, X. L. Xu et al., "Spatial patterns and driving forces of land use change in china in the early 21st century," Acta Geographica Sinica, vol. 64, pp. 1411-1420, 2009. 
[31] Y. R. Zou, Z. X. Zhang, Q. B. Zhou et al., "Land use change dynamics spatial pattern in ecotone between agriculture and animal husbandry and its driving force analysis," Journal of Natural Resources, vol. 18, pp. 222-227, 2003.

[32] M. Güler, T. Yomralioğu, and S. Reis, "Using landsat data to determine land use/land cover changes in samsun, turkey," Environmental Monitoring and Assessment, vol. 127, no. 1-3, pp. 155-167, 2007.

[33] X. D. Du, X. B. Jin, X. Yang H et al., "Spatial pattern of land use change and its driving force in Jiangsu Province," International Journal of Environmental Research \& Public Health, vol. 11, pp. 3215-3232, 2014.

[34] J. Marull, J. Pino, E. Tello, and M. J. Cordobilla, "Social metabolism, landscape change and land-use planning in the Barcelona Metropolitan Region," Land Use Policy, vol. 27, no. 2, pp. 497-510, 2010.

[35] S. Balaselvakumar, E. V. R. College, and P. Sujatha, "Landuse and landcover change detection in lalgudi block, tiruchirappalli district - using remote sensing and GIS techniques," International Journal of Engineering Research and Applications, vol. 5, pp. 108117, 2015.

[36] W. H. Yu, T. H. Ai, M. Yang et al., “Detecting 'Hot spots' of facility POIs Based on kernel density estimation and spatial autocorrelation technique," Geomatics and Information Science of Wuhan University, vol. 41, pp. 221-227, 2016.

[37] L. Zhang, G. F. Yang, and J. P. Liu, "The dynamic change and Hot spots of land use in Fushun city," Scientia Geographica Sinica, vol. 34, pp. 185-191, 2014.

[38] F. J. Gao, L. Q. Ma, Shan. M. P. et al., "Land use/cover change and hot spots analysis in muling city of helongjiang province," Areal Research and Development, vol. 35, pp. 126-130, 2016.

[39] C. Y. Guo, "Land use transiton and hotspots detection in yongcheng city base on the grid scale," China Land Sciences, vol. 30, pp. 43-51, 2016.

[40] P. Singh and K. Khanduri, "Land use and land cover change detection through remote sensing gis technology: case study of pathankot and dhar kalan tehsils, Punjab," International Journal of Geomatics \& Geosciences, pp. 839-846, 2010.

[41] S. Khan, S. Qasim, R. Ambreen, and Z. Syed, "Spatio-temporal analysis of landuse/landcover change of district pishin using satellite imagery and GIS," Journal of Geographic Information System, vol. 8, no. 3, pp. 361-368, 2016.

[42] H. J. Geist, "Change or collapse? A theoretical approach to global environmental change and landuse in rainforest and arid zone hotspots," Geographische Zeitschrift, vol. 94, no. 3, pp. 143159, 2006.

[43] S. B. Hao and H. W. Wang, "Spatial structure research of urban agglomeration in Jing-Jin-Ji," Inquiry into Economic Issues, vol. 6, pp. 105-111, 2015.

[44] D. J. Fu, Construction of the Four Major Functional Areas Based on Integration of Jing-Jin-Ji Region, Minzu University of China, 2015.

[45] X. F. Gong, "Development driving force of Jing-Jin-Ji region," The World of Real Estate, vol. 8, pp. 86-89, 2015.

[46] D. Meng, "Analysis of spatial-temporal change of NDVI and its climatic driving factors in Beijing-Tianjin-Hebei metropolis circle from 2001 to 2013," Journal of Geo-Information Science, vol. 17, pp. 1001-1007, 2015.

[47] J. Liu, Z. Zhang, X. Xu et al., "Spatial patterns and driving forces of land use change in China during the early 21st century," Journal of Geographical Sciences, vol. 20, no. 4, pp. 483-494, 2010.
[48] Z. X. Zhang, X. L. Zhao, X. Wang et al., Remote Sensing Monitoring of Land Use in China, Star Maps Publishing, Beijing, China, 2012.

[49] J. Y. Liu, M. L. Liu, D. F. Zhuang, Z. X. Zhang, and X. Z. Deng, "Study on spatial pattern of land-use change in China during 1995-2000," Science China Earth Science, vol. 46, no. 4, pp. 373384, Ser. D 2003.

[50] J. Y. Liu, J. Y. Zhan, and X. Z. Deng, "Spatio-temporal patterns and driving forces of urban land expansion in china during the economic reform era," Ambio, vol. 34, pp. 450-455, 2005.

[51] J. Liu, Q. Zhang, and Y. Hu, "Regional differences of China's urban expansion from late 20th to early 21st century based on remote sensing information," Chinese Geographical Science, vol. 22, no. 1, pp. 1-14, 2012.

[52] S. Y. Wang, J. Y. Liu, Z. X. Zhang et al., "Analysis on spatialtemporal features of land use in China," Acta Geographica Sinica, vol. 56, pp. 631-639, 2001.

[53] D. J. Redo, T. M. Aide, M. L. Clark, and M. J. Andrade-Núñez, "Impacts of internal and external policies on land change in Uruguay, 2001-2009," Environmental Conservation, vol. 39, no. 2, pp. 122-131, 2012.

[54] L. Yi, Z. X. Zhang, X. Wang et al., "Spatial-temporal change of major reserve resources of arable land in China in recent 30 years," Transaction of the CSAE, vol. 29, pp. 1-12, 2013.

[55] H. P. Zhao, Y. H. Zhu, K. N. Wu et al., "Study on the method for the demarcation of urban-rural fringe based on land use dynamic indicator," China Land Sciences, vol. 26, pp. 60-65, 2012.

[56] J. Y. Liu, Z. X. Zhang, D. F. Zhuang et al., "A study on the spatial-temporal dynamic changes of landuse and driving forces analyses of China in the 1990s," Geographical Research, vol. 22, pp. 1-12, 2003.

[57] P. Pfaffenbichler, G. Emberger, and S. Shepherd, "The integrated dynamic land use and transport model MARS," Networks and Spatial Economics, vol. 8, no. 2-3, pp. 183-200, 2008.

[58] J. F. Wang, Spatial Data Analysis Tutorial, Science Press, 2010.

[59] V. De Oliveira and M. D. Ecker, "Bayesian hot spot detection in the presence of a spatial trend: application to total nitrogen concentration in Chesapeake Bay," Environmetrics, vol. 13, no. 1, pp. 85-101, 2002.

[60] Q. Pan, X. B. Jin, and Y. K. Zhou, "Gridding reconstruction of land use pattern in Jiangsu province in the mid-qing dynasty," Acta Geographica Sincia, vol. 70, pp. 1449-1462, 2015.

[61] M. Meroni, D. Fasbender, F. Kayitakire et al., "Early detection of biomass production deficit hot-spots in semi-arid environment using FAPAR time series and a probabilistic approach," Remote Sensing of Environment, vol. 142, pp. 57-68, 2014. 


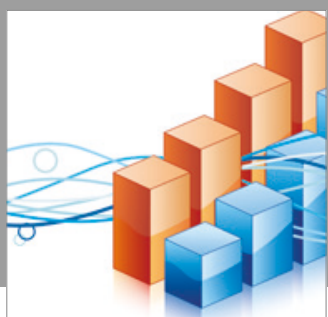

Advances in

Operations Research

vatersals

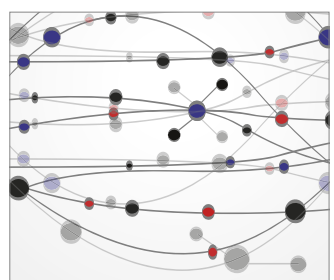

\section{The Scientific} World Journal
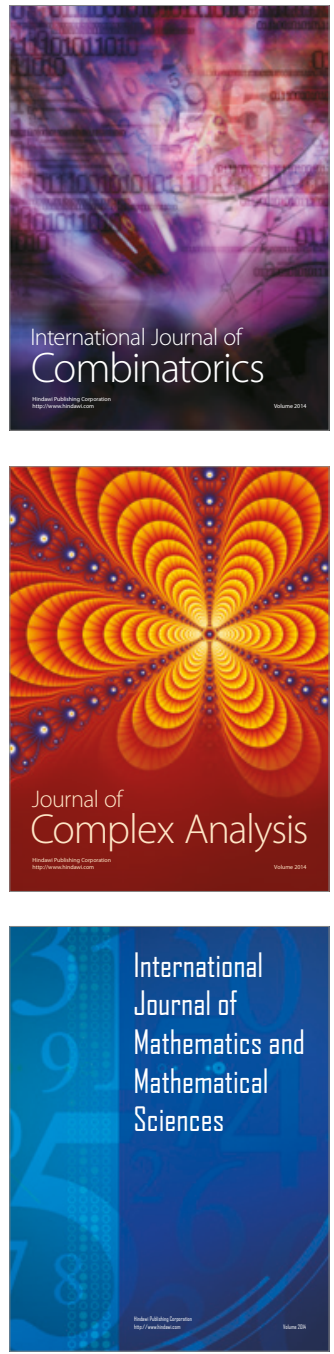
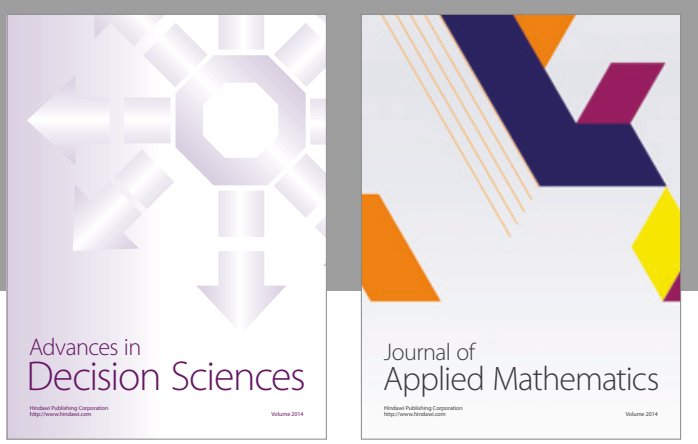

Algebra

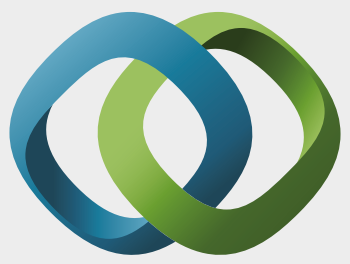

\section{Hindawi}

Submit your manuscripts at

https://www.hindawi.com
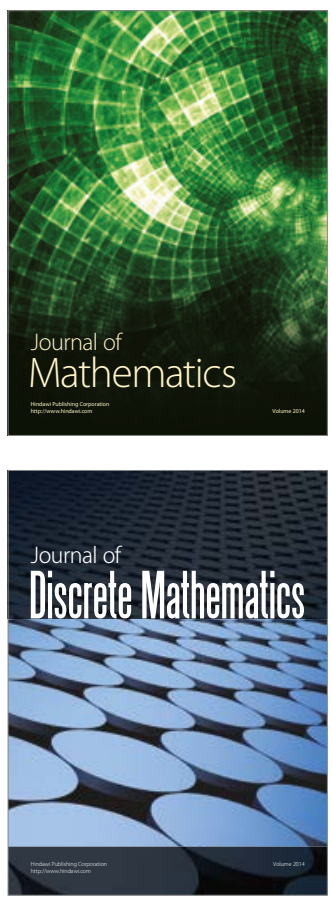

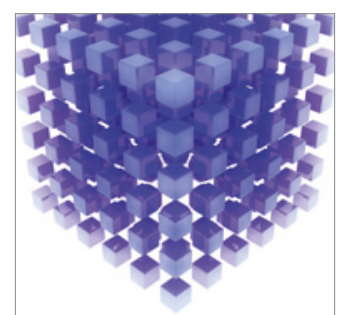

Mathematical Problems in Engineering
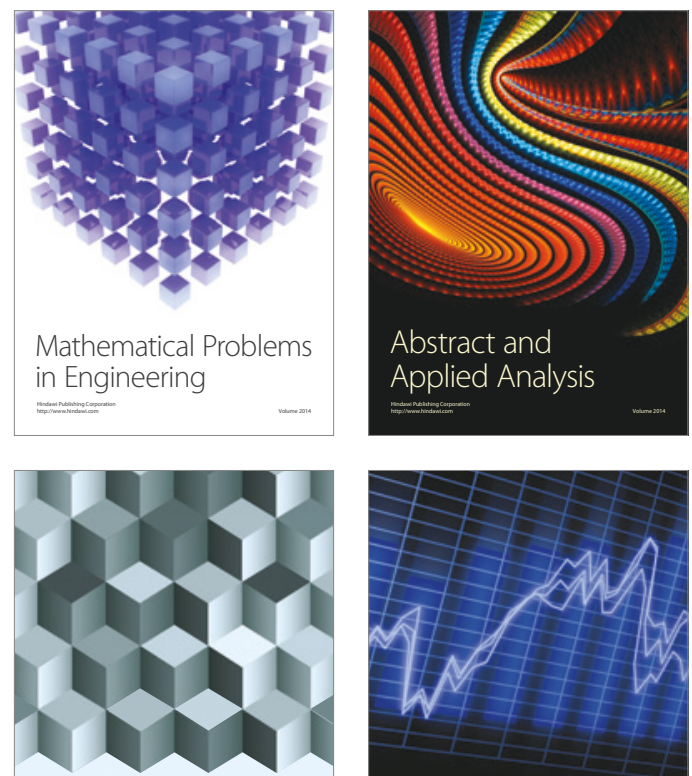

Journal of

Function Spaces

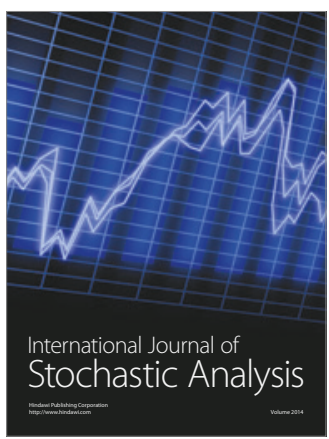

Probability and Statistics
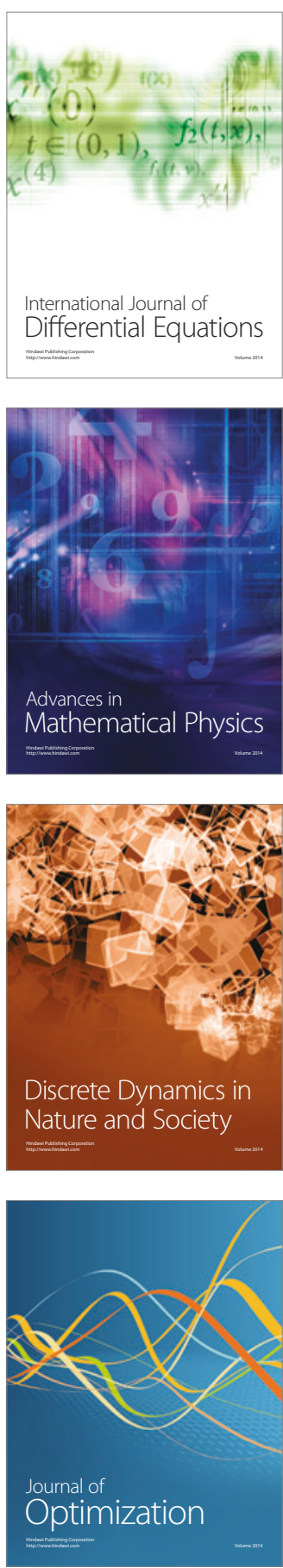